\title{
Surgery-related predictors of kneeling ability following total knee arthroplasty: a systematic review and meta-analysis
}

Shaheer Nadeem ${ }^{1 *} \mathbb{0}$, Raman Mundi ${ }^{2,3}$ and Harman Chaudhry ${ }^{2,3}$

\begin{abstract}
Purpose: Kneeling ability is among the poorest outcomes following total knee arthroplasty (TKA). The purpose of this meta-analysis was to: (1) quantify kneeling ability after TKA; (2) identify surgical approaches and prosthesis designs that improve kneeling ability following TKA; and (3) quantify the effectiveness of these approaches.

Methods: We performed a systematic review in accordance with the PRISMA guidelines of multiple medical databases. Data relating to demographics, TKA technique, prosthesis design, and kneeling-specific outcomes were extracted. Comparative outcomes data were pooled using a random effects model.

Results: Thirty-six studies met the eligibility criteria. The proportion of patients able to kneel increased with longer follow-up (36.8\% at a minimum of 1 year follow-up versus $47.6 \%$ after a minimum of 3 years follow-up, $p<0.001$ ). The odds of kneeling were greater for patients undergoing an anterolateral incision compared with an anteromedial incision (OR 3.0, 95\% Cl 1.3-6.9, $p=0.02)$; a transverse incision compared with a longitudinal incision $(\mathrm{OR} 3.5,95 \% \mathrm{Cl}$ $1.4-8.7, p=0.008)$; and a shorter incision compared with a longer incision (OR 8.5, 95\% Cl 2.3-30.9, $p=0.001)$. The odds of kneeling were worse for a mobile prosthesis compared with a fixed platform design (OR 0.3, 95\% Cl 0.1-0.7, $p=0.005$ ).

Conclusion: A large majority of patients are unable to kneel following TKA, although the ability to kneel improves over time. This evidence may facilitate preoperative patient counseling. Variations in choice of incision location and length may affect ability to kneel; however, high-quality randomized trials are needed to corroborate our findings.
\end{abstract}

Keywords: Arthroplasty, Kneel, Knee replacement, Primary

\section{Introduction}

Total knee arthroplasty (TKA) is the definitive surgical treatment for patients with pain and disability attributable to end-stage degenerative knee joint disease. Although a generally successful procedure, a large minority of patients (ranging from $8 \%$ to $25 \%$ ) remain

*Correspondence: nadees15@mcmaster.ca

${ }^{1}$ Faculty of Health Sciences, McMaster University, 1280 Main St W, Hamilton, ON L8S 4L8, Canada

Full list of author information is available at the end of the article dissatisfied after surgery [1]. While a few of these patients may have suffered from complications-such as infection, instability, or prosthesis loosening-most have wellfunctioning knees but suffer from so-called nuisance symptoms, among which inability to kneel figures prominently [2].

Kneeling involves placing both knees on the ground and is important for many daily activities. It also holds significant cultural, religious, and occupational value for patients [3-5]. Ninety-four percent of patients expect to be able to kneel 1 year after TKA [6]. Thus, kneeling

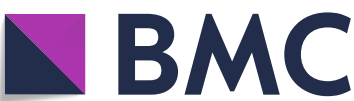

Part of Springer Nature
(O) The Author(s) 2021. Open Access This article is licensed under a Creative Commons Attribution 4.0 International License, which permits use, sharing, adaptation, distribution and reproduction in any medium or format, as long as you give appropriate credit to the original author(s) and the source, provide a link to the Creative Commons licence, and indicate if changes were made. The images or other third party material in this article are included in the article's Creative Commons licence, unless indicated otherwise in a credit line to the material. If material is not included in the article's Creative Commons licence and your intended use is not permitted by statutory regulation or exceeds the permitted use, you will need to obtain permission directly from the copyright holder. To view a copy of this licence, visit http://creativecommons.org/licenses/by/4.0/. The Creative Commons Public Domain Dedication waiver (http://creativeco mmons.org/publicdomain/zero/1.0/) applies to the data made available in this article, unless otherwise stated in a credit line to the data. 
is of significant importance to TKA candidates and a key element of patient satisfaction. There are few studies that focus on kneeling ability as a primary outcome. Where kneeling has been evaluated, the percentage of patients able to comfortably kneel after TKA has varied greatly from $12 \%$ to $90 \%[7,8]$. Patients who are unable to kneel have cited pain and discomfort, a lack of education on appropriate kneeling technique, and fear of harming their implant as reasons for refraining from kneeling [7]. Further, little research to date has focused on surgical predictors of kneeling ability. To improve outcomes following TKA, it is important to identify the prevalence of kneeling issues among TKA patients and perioperative interventions to improve post-TKA kneeling outcomes.

The purpose of this systematic review and meta-analysis was: (1) to determine the prevalence of kneeling difficulties in patients who have undergone TKA; (2) to identify approaches that may improve kneeling ability; and (3) to quantify the effectiveness of these approaches.

\section{Methods}

This study was conducted according to the guidelines presented in the Preferred Reporting Items for Systematic Reviews and Meta-Analyses statement (PRISMA) [9].

\section{Assessment of kneeling ability}

For studies reporting dichotomous data, kneeling ability was assessed by the number of patients able to successfully kneel. In studies where categorical data on kneeling ability were provided, such as those that used the Knee Injury and Osteoarthritis Outcome Score, or other TKA outcome scales, patients were considered able to kneel if they could do so with mild to no discomfort.

\section{Eligibility criteria}

Studies were eligible for inclusion if patients had undergone primary TKA and postoperative kneeling outcomes data were reported. Any studies not in English were excluded.

\section{Search strategy}

A comprehensive literature search was conducted in MEDLINE and EMBASE from inception to May 2020. Keywords used in the searches were "knee arthroplasty" OR "knee replacement" " AND "kneel"." Cited articles were also searched manually to identify any additional studies that were potentially eligible for inclusion.

\section{Article screening}

After executing the search strategy, duplicate articles were removed. The titles and abstracts of the remaining studies were screened by two independent reviewers according to the prespecified eligibility criteria. The remaining studies were then screened using full text by the reviewers. Any disagreements between the reviewers on study inclusion were resolved through discussion and consultation with a second senior author.

\section{Data extraction}

Data were independently extracted by two reviewers into a premade spreadsheet. Information on study characteristics, patient demographics, and kneeling-specific outcomes was noted. Any discrepancies during data extraction were resolved through discussion between reviewers and in consultation with a third reviewer.

\section{Statistical analysis}

Studies were split into two groups based on design. For noncomparative studies, the proportion of patients able to kneel at $\leq 1$ year, minimum 1 year, and minimum 3 years follow-up was calculated. Statistical significance based on follow-up times was determined using the $x^{2}$ statistical test. Comparative studies were analyzed separately based on surgical approach or prosthesis design. A random effects model was used to pool outcomes data and determine odds ratios (OR), 95\% confidence intervals $(\mathrm{CI})$, and $p$-values. A $p$-value $\leq 0.05$ was considered as being statistically significant for all analyses.

\section{Risk of bias assessment}

Study quality was independently assessed by two authors. Randomized control trials (RCTs) were assessed using the revised version of the Cochrane risk-of-bias tool for randomized trials [10]. The remaining studies were assessed for quality using the Methodological Index for Non-Randomized Studies (MINORS) [11].

\section{Results}

\section{Search results}

After search retrieval, 384 potential articles were found with 129 duplicates. A total of 255 title and abstracts were screened for eligibility. After the initial screening, 61 studies met the inclusion criteria, and their full text was evaluated. A total of 36 studies were included in the systematic review. A flow chart detailing reasons for study exclusion is provided as Fig. 1.

Approximately $94 \%$ of the studies occurred at a singlecenter institution, with the majority being conducted in Europe (42\%). Studies were published between 1999 and 2020 and in total featured 12,626 TKA patients at the latest follow-up time. Twenty-one of the studies were prospective cohort, eight were cross-sectional, five were retrospective chart reviews, and two were RCTs. The number of comparative studies was less than the number of noncomparative studies, 11 versus 25 , respectively. All of the 


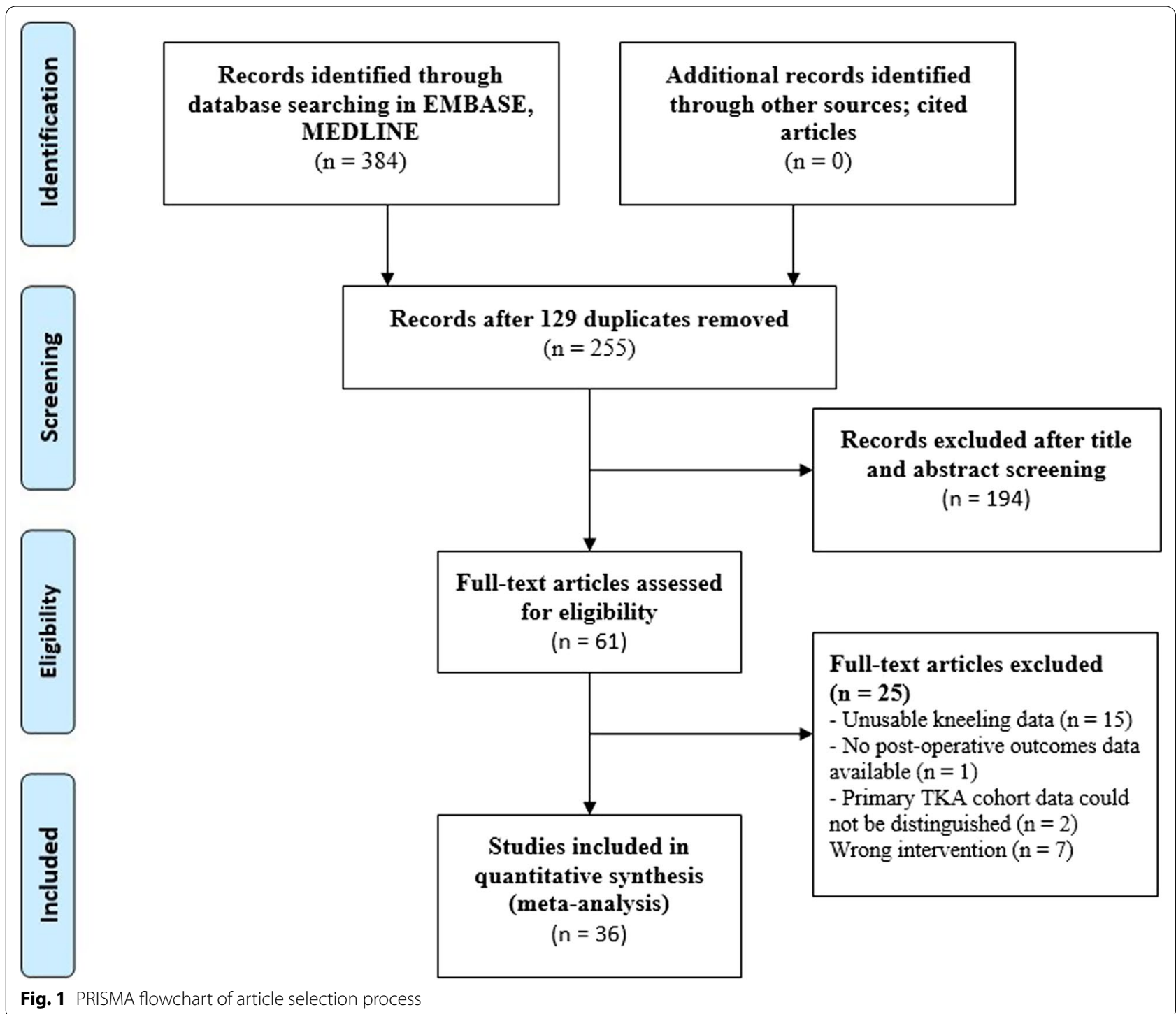

studies were written in the English language. A detailed outline of study characteristics is presented in Table 1.

\section{Study quality}

For noncomparative studies, the mean MINORS score was 11.2 (range 6-14). The mean MINORS score for comparative studies was 18.4 (range 16-20). In both RCTs, there was some concerns in the selection of reported results, but low risk of bias in all other domains. The overall rating for both RCTs suggested some risk of bias.

\section{Overall kneeling ability}

Thirteen noncomparative studies evaluated kneeling ability at $\leq 1$ year follow-up, 24 studies at minimum 1 year follow-up, and 9 studies at minimum 3 years follow-up. The proportion of patients able to kneel increased based on follow-up duration; $34.5 \%$ at $\leq 1$ year (95\% CI 33.5$35.5 \%), 36.8 \%$ at minimum 1 year (95\% CI $35.9-37.7 \%$ ), and $47.6 \%$ at minimum 3 years ( $95 \%$ CI $45.6-49.6 \%)$. The difference in kneeling ability at $1-3$ years and $>3$ years follow-up was statistically significant $(p<0.001)$. Overall, the number of patients analyzed at a follow-up time of at least 1 year was 11,514 and 2441 at minimum 3 years follow-up.

\section{Surgical predictors of kneeling ability}

Three surgical approaches showed a statistically significant improvement in kneeling ability after TKA. Kneeling odds were greater for patients undergoing a transverse 
Table 1 Summary of study characteristics

\begin{tabular}{lc}
\hline Characteristic & Studies, no. (\%) \\
\hline Location & $9(25)$ \\
East Asia & $1(3)$ \\
South Asia & $15(42)$ \\
Europe & $10(28)$ \\
North America & $1(3)$ \\
Other & \\
No. of institutions & $34(94)$ \\
Single center & $2(6)$ \\
Multicenter & \\
Sample size (TKA patients only) & $13(36)$ \\
$<100$ & $19(53)$ \\
100-400 & $4(11)$ \\
$>400$ & \\
Type of study & $2(6)$ \\
Randomized control trial & $21(58)$ \\
Prospective cohort & $5(14)$ \\
Retrospective cohort & $8(22)$ \\
Cross-sectional &
\end{tabular}

incision compared with a longitudinal incision (OR 3.5, 95\% CI 1.4-8.7, $p=0.008$ ), an anterolateral incision compared with an anteromedial incision (OR 3.0, 95\% CI 1.3-6.9, $p=0.02$ ), and a shorter incision (mean $10.5 \mathrm{~cm}$ ) compared with a longer incision (mean $18.5 \mathrm{~cm}$ ) (OR 8.5, 95\% CI 2.3-30.9, $p=0.001$ ). Only one prosthesis design showed a significant difference in kneeling ability. The odds of kneeling were lower using a mobile prosthesis versus a fixed platform design at 2 years follow-up (OR $0.3,95 \%$ CI $0.1-0.7, p=0.005)$. A summary of kneeling outcomes for comparative studies is outlined in Table 2 [12-22].

\section{Discussion}

This systematic review aimed to quantify the number of patients able to kneel after TKA and determine the effectiveness of surgical approaches and prosthesis designs in improving kneeling results. Pooled results showed that kneeling ability increased with a longer follow-up duration, with $36.8 \%$ of patients able to kneel at a minimum of 1 year follow-up and $47.6 \%$ able to kneel at a minimum of 3 years follow-up. Among comparative studies, a shorter incision length greatly improved the odds of kneeling compared with a longer incision (OR 5.6, 95\% CI 2.3-30.9, $p=0.001$ ), a transverse incision increased the odds of kneeling versus a longitudinal incision (OR 3.5, $p=0.008$ ), and an anterolateral incision was superior to an anteromedial incision (OR 3.0, $p=0.02$ ). Overall, variations of prosthesis design showed limited changes in kneeling ability, with only a single study demonstrating that a fixed platform design increased kneeling odds compared with a mobile design (OR 3.3, $p=0.005$ ).

Prior to TKA, $80-95 \%$ of patients have high expectations of being able to kneel after surgery [23]. When high preoperative expectations are not met, they can negatively impact patient satisfaction [24-26]. This study found that approximately two-thirds of patients are unable to kneel after at least 1 year post surgery and around half of patients cannot kneel 3 or more years after TKA. The improvement in kneeling ability with longer followup times may be attributable to a number of different reasons. Increased numbness-from sensory nerve damage during surgery-is correlated with poorer kneeling ability and is a common symptom reported by patients unable to kneel [27]. Numbness in the knee joint decreases with longer follow-up times, which may allow more patients to kneel [28]. Moreover, some patients choose not to kneel due to pain and discomfort after TKA [7]. Since a reduction in pain and swelling is greatest in the first year after surgery [29-31], more patients in studies with longer follow-up times may be able to kneel. Discomfort after TKA may also be caused by early instability of the joint, and patients with such complications may not be selected for in studies with longer follow-up times [32].

Variations of incision types showed the greatest benefit in kneeling ability after TKA. Minimally invasive surgery (MIS) with a smaller incision length (mean $10.5 \mathrm{~cm}$ ) significantly increased odds of kneeling compared with a standard incision (mean $18.5 \mathrm{~cm}$ ). It is important to recognize that, although MIS may improve functional outcomes, there is a steep learning curve associated with the procedure and significant stress on soft tissues during retraction [33]. Moreover, some studies suggest that the functional benefits of MIS TKA may only last several months to a year [34, 35]. This review also found that an anterolateral incision was superior to an anteromedial incision in terms of kneeling ability. Lateral incisions have been found to pose a smaller risk of damage to the infrapatellar branch of the saphenous nerve compared with a midline incision [36]. Since alteration of skin sensation around the incision decreases kneeling ability [37], lateral incisions may improve kneeling outcomes because of a lower risk of nerve damage. A single study found that a transverse incision improved kneeling ability and scar cosmesis compared with a longitudinal incision [17]. Similar to a lateral incision, a transverse incision is associated with a lower risk of sensory disturbance from damage to the infrapatellar branch of the saphenous nerve. However, this technique requires greater subcutaneous dissection and increases operating time [17]. More high-quality studies are needed to fully understand the benefits and drawbacks of various surgical approaches on kneeling ability. 
Variations of prosthesis design and patellar resurfacing failed to demonstrate any considerable improvement in kneeling ability. Artz et al. [19] suggested that a fixed platform design increased the odds of kneeling compared with a mobile design at 2 years follow-up. However, when outcomes data were pooled, no significant differences in the odds of kneeling were noted at 1 year follow-up (OR $0.6,95 \%$ CI $0.3-1.2, p=0.14)$. Some prosthesis designs, such as high flexion, may offer benefits such as increased range of motion [38]; however, this did not translate to improved kneeling ability. Similarly, although patellar resurfacing did not demonstrate any functional benefit in this study, a meta-analysis suggested that resurfacing can substantially reduce the need for reoperation [39]. Orthopedic surgeons should weigh the benefits and drawbacks of each intervention, in consultation with patients, to improve outcomes.

Although this study investigated surgery-related predictors of kneeling ability post-TKA, rehabilitation programs may also have an effect. Patient education programs on proper kneeling technique have previously shown some success [40]. Moreover, unilateral or bilateral TKA may also influence kneeling ability. In this study, patients with partial TKA were excluded. Future research should also compare kneeling outcomes between these subsets of patients.

\section{Strengths and limitations}

This systematic review has a number of strengths that help to validate our results. The methodology used for this study was in accordance with PRISMA guidelines [9], thereby ensuring that our methods were robust and standardized. Moreover, we broadly searched multiple electronic databases and supplemented our results by manually searching cited articles. A large sample size of 11,614 patients were assessed for kneeling ability in noncomparative studies, thus further strengthening our conclusions for overall kneeling ability.

This study pooled outcomes data from several different articles, thus limiting the results owing to the quality and heterogeneity of the original data. Not all studies reported the same types of outcomes data, and those that did may not be suitable for a meta-analysis. Since kneeling ability was measured in all studies, it is suitable to be included in a pooled analysis model. It is also important to acknowledge that many comparative studies were observational in design or reported a small sample size. As such, findings from such studies should be considered preliminary, and further research is required. It is also important to acknowledge that a patient's actual kneeling ability may deviate up to $32 \%$ from their perceived ability [41]. Thus, the findings of this systematic review are limited due to the variation in kneeling

Table 2 Pooled kneeling results from comparative studies

\begin{tabular}{|c|c|}
\hline Comparison & Differences in ability to kneel \\
\hline High-flexion versus conventional TKA design & $\begin{array}{l}\text { No difference between groups ( } 46 \% \text { in high flexion TKA versus } 44 \% \text { in conventional TKA, OR 1.1, } \\
95 \% \mathrm{Cl} 0.5-2.4, p=0.84 \text { ) Seon et al. [12] }\end{array}$ \\
\hline Patellar resurfacing versus non-resurfacing & $\begin{array}{l}\text { No difference between groups (42.7\% without resurfacing versus } 35.0 \% \text { with resurfacing; OR 1.6, } \\
95 \% \mathrm{Cl} 0.6-4.4, p=0.35 \text { ) Huish et al. [13]; Garneti et al. [14] }\end{array}$ \\
\hline Anterolateral versus midline/medial skin incision & $\begin{array}{l}\text { No difference between groups (80.8\% with anterolateral incision versus 58.3\% with anteromedial } \\
\text { incision; OR 3.0, 95\% Cl 1.3-6.9, } p=0.02) \text { Tsukada et al. [15] }\end{array}$ \\
\hline $\begin{array}{l}\text { Mini-length (mean } 10.5 \mathrm{~cm} \text { ) versus standard length } \\
\text { (mean } 18.5 \mathrm{~cm} \text { ) midline skin incision }\end{array}$ & $\begin{array}{l}\text { Significant difference between groups ( } 40 \% \text { with MIS versus } 0 \% \text { with standard surgery at } \\
6 \text { months; OR } 34.6,95 \% \mathrm{Cl} 1.9-631.9, p=0.02 \text { and } 80 \% \text { with MIS versus } 32 \% \text { with standard surgery } \\
\text { at } 2 \text { years; OR } 8.595 \% \mathrm{Cl} 2.3-30.9, p=0.001 \text { ) Kashyap et al. [16] }\end{array}$ \\
\hline Transverse versus longitudinal skin incision & $\begin{array}{l}\text { Significant difference between groups ( } 70.4 \% \text { with transverse incision versus } 40.6 \% \text { with longitu- } \\
\text { dinal incision; OR 3.5, 95\% Cl 1.4-8.7, p=0.008) Ojima et al. [17] }\end{array}$ \\
\hline Mobile versus fixed platform design & $\begin{array}{l}\text { No difference between groups at 1-year follow-up (25.6\% with mobile prosthesis versus } 36.4 \% \\
\text { with fixed design; OR 0.6, } 95 \% \mathrm{Cl} 0.3-1.2, p=0.14 \text { ) Kim et al. [18]; Artz et al. [19] } \\
\text { Mobile platform inferior to fixed platform at 2-year follow-up (10.8\% able to kneel with little or no } \\
\text { difficulty with mobile prosthesis versus } 27.5 \% \text { with fixed design; OR 0.3, } 95 \% \mathrm{Cl} 0.1-0.7, p=0.005 \text { ) } \\
\text { Artz et al. [19] }\end{array}$ \\
\hline Two different mobile-bearing prosthesis designs & $\begin{array}{l}\text { No difference between groups (37.5\% with rotation platform versus } 21.1 \% \text { with mobile design; } \\
\text { OR 2.3, } 95 \% \mathrm{Cl} 0.5-10.1, p=0.29 \text { ) Nam et al. [20] }\end{array}$ \\
\hline High-flexion versus mobile platform design & $\begin{array}{l}\text { No difference between groups ( } 40 \% \text { in high-flexion group versus } 36 \% \text { with fixed design; OR 1.2, } \\
95 \% \mathrm{Cl} 0.5-2.7, p=0.68 \text { ) Seon et al. [21] }\end{array}$ \\
\hline Cruciate-retaining versus posterior-stabilized design & $\begin{array}{l}\text { No difference between groups (40.0\% for cruciate retaining versus } 37.5 \% \text { for posterior substitut- } \\
\text { ing design; OR 1.1,95\% Cl 0.4-3.1, } p=0.84 \text { ) Zhang et al. [22] }\end{array}$ \\
\hline
\end{tabular}


assessment between studies, i.e., patient self-reporting and external validation.

The studies included in this systematic review were subject to varying degrees of bias. Many comparative studies received a low MINORS rating due to unblinded assessment of the endpoint. Although blinding assessors to kneeling ability would not have been difficult, few studies reported this information. As such, it is not possible to determine if the assessment of kneeling ability was unduly influenced by external factors. Similarly, many nonrandomized studies received a low MINORS score due to nonprospective calculation of sample size. It is not possible to determine if kneeling ability was over- or underreported in some studies owing to improper sample size. For both RCTs assessed in this study, there was some concern for bias under the selection of reported outcomes domain. Neither of the RCTs listed a prespecified analysis plan. Therefore, it was not possible to ascertain if reporting bias was present.

\section{Conclusion}

Many patients may not meet their expectations of kneeling ability after TKA, as a large majority of patients are unable to kneel. The ability to kneel tends to improve over time, with significantly more patients able to kneel at a minimum of 3-year follow-up in comparison with 1-year follow-up. This evidence may facilitate preoperative patient counseling.

Limited evidence suggests that variations in choice of incision location and length may affect ability to kneel. High-quality randomized trials are needed to evaluate potential perioperative interventions that can improve kneeling in patients after TKA, and to further corroborate our findings.

\section{Abbreviations}

TKA: Total knee arthroplasty; PRISMA: Preferred Reporting Items for Systematic Reviews and Meta-Analyses statement; OR: Odds ratio; Cl: Confidence interval; MINORS: Methodological Index for Non-Randomized Studies; RCT: Randomized controlled trial; MIS: Minimally invasive surgery.

\section{Acknowledgements}

Not applicable.

\section{Authors' contributions}

$\mathrm{HC}$ and RM conceived the idea for the project. SN and HC designed and executed the literature search. SN, RM, and HC screened articles, extracted data, and completed risk of bias assessment. SN conducted the statistical analysis and wrote the manuscript under the supervision of $\mathrm{HC}$. RM and $\mathrm{HC}$ reviewed the manuscript and suggested revisions. All authors approved the manuscript before submission. All authors read and approved the final manuscript.

\section{Funding}

No external funding was obtained for this study.

\section{Availability of data and materials}

Please contact the corresponding author for information about datasets used in this study.

\section{Declarations}

Ethics approval and consent to participate

Not applicable (all primary articles incorporated in this systematic review and meta-analysis reported adequate ethics approval procedures).

\section{Competing interests}

The authors declare that they have no competing interests.

\section{Author details}

${ }^{1}$ Faculty of Health Sciences, McMaster University, 1280 Main St W, Hamilton, ON L8S 4L8, Canada. ${ }^{2}$ Division of Orthopaedic Surgery, University of Toronto, 149 College Street, Toronto, ON M5T 1P5, Canada. ${ }^{3}$ Sunnybrook Holland Orthopaedic and Arthritic Centre, 43 Wellesley St E, Toronto, ON M4Y 1H1, Canada.

Received: 15 July 2021 Accepted: 14 September 2021

Published online: 02 October 2021

\section{References}

1. Choi YJ, Ra HJ (2016) Patient satisfaction after total knee arthroplasty. Knee Surg Relat Res 28(1):1-15. https://doi.org/10.5792/ksrr.2016.28.1.1

2. Weiss JM, Noble PC, Conditt MA, Kohl HW, Roberts S, Cook KF, Gordon MJ, Mathis KB (2002) What functional activities are important to patients with knee replacements? Clin Orthop Relat Res 404:172-188. https://doi.org/ 10.1097/00003086-200211000-00030

3. Anderson JJ, Felson DT (1988) Factors associated with osteoarthritis of the knee in the first national Health and Nutrition Examination Survey (HANES I). Evidence for an association with overweight, race, and physical demands of work. Am J Epidemiol 128(1):179-189. https://doi.org/10. 1093/oxfordjournals.aje.a114939

4. Coggon D, Croft P, Kellingray S, Barrett D, McLaren M, Cooper C (2000) Occupational physical activities and osteoarthritis of the knee. Arthritis Rheum 43(7):1443-1449. https://doi.org/10.1002/1529-0131(200007) 43:7\%3c1443:.:aid-anr5\%3e3.0.co;2-1

5. Fletcher D, Moore AJ, Blom AW, Wylde V (2019) An exploratory study of the long-term impact of difficulty kneeling after total knee replacement. Disabil Rehabil 41(7):820-825. https://doi.org/10.1080/09638288.2017. 1410860

6. de Achaval S, Kallen MA, Amick B, Landon G, Siff S, Edelstein D, Zhang H, Suarez-Almazor ME (2016) Patients' expectations about total knee arthroplasty outcomes. Health Expect 19(2):299-308. https://doi.org/10. 1111/hex.12350

7. Sabeh KG, Hernandez VH, Cohen-Levy WB, Ong A, Orozco F, Bennett V, Post Z (2019) The effects of patient occupation, hobbies, and body mass index on kneeling after total knee arthroplasty. J Knee Surg. https://doi. org/10.1055/s-0039-3400740

8. Jain S, Pathak AC, Kalaivanan K (2016) Minimum 5-year follow-up results and functional outcome of rotating- platform high-flexion total knee arthroplasty: a prospective study of 701 knees. Arthroplast Today 2(3):127-132. https://doi.org/10.1016/j.artd.2016.01.006

9. Moher D, Liberati A, Tetzlaff J, Altman DG (2010) Preferred reporting items for systematic reviews and meta-analyses: the PRISMA statement. Int J Surg 8(5):336-341. https://doi.org/10.1016/j.jjsu.2010.02.007

10. Higgins JP, Altman DG, Gotzsche PC, Juni P, Moher D, Oxman AD, Savovic J, Schulz KF, Weeks L, Sterne JA (2011) The Cochrane Collaboration's tool for assessing risk of bias in randomised trials. BMJ 343:d5928. https://doi. org/10.1136/bmj.d5928

11. Slim K, Nini E, Forestier D, Kwiatkowski F, Panis Y, Chipponi J (2003) Methodological index for non-randomized studies (minors): development and validation of a new instrument. ANZ J Surg 73(9):712-716. https://doi. org/10.1046/j.1445-2197.2003.02748.x

12. Seon JK, Park SJ, Lee KB, Yoon TR, Kozanek M, Song EK (2009) Range of motion in total knee arthroplasty: a prospective comparison of highflexion and standard cruciate-retaining designs. J Bone Joint Surg Am 91(3):672-679. https://doi.org/10.2106/jbjs.h.00300

13. Huish EG Jr, Coury JG, Ummel JR, Deans JT, Cohen J, Casey JJ Jr (2020) Higher rate of kneeling after primary knee arthroplasty without patellar 
resurfacing at midterm review. J Orthop 20:204-206. https://doi.org/10. 1016/j.jor.2019.11.008

14. Garneti N, Mahadeva D, Khalil A, McLaren CA (2008) Patellar resurfacing versus no resurfacing in Scorpio total knee arthroplasty. J Knee Surg 21(2):97-100. https://doi.org/10.1055/s-0030-1247802

15. Tsukada S, Kurosaka K, Nishino M, Hirasawa N (2018) Cutaneous hypesthesia and kneeling ability after total knee arthroplasty: a randomized controlled trial comparing anterolateral and anteromedial skin incision. J Arthroplasty 33(10):3174-3180. https://doi.org/10.1016/j.arth.2018.06.010

16. Kashyap SN, van Ommeren JW (2008) Clinical experience with less invasive surgery techniques in total knee arthroplasty: a comparative study. Knee Surg Sports Traumatol Arthrosc 16(6):544-548. https://doi.org/10. 1007/s00167-008-0523-0

17. Ojima T, Yoshimura M, Katsuo S, Mizuno K, Yamakado K, Hayashi S, Tsuchiya H (2011) Transverse incision advantages for total knee arthroplasty. J Orthop Sci 16(5):524-530. https://doi.org/10.1007/ s00776-011-0133-4

18. Kim TW, Park SH, Suh JT (2012) Comparison of mobile-bearing and fixedbearing designs in high flexion total knee arthroplasty: using a navigation system. Knee Surg Relat Res 24(1):25-33. https://doi.org/10.5792/ksrr. 2012.24.1.25

19. Artz NJ, Hassaballa MA, Robinson JR, Newman JH, Porteous AJ, Murray JR (2015) Patient reported kneeling ability in fixed and mobile bearing knee arthroplasty. J Arthroplasty 30(12):2159-2163. https://doi.org/10.1016/j. arth.2015.06.063

20. Nam SW, Lee YS, Kwak JH, Kim NK, Lee BK (2012) A comparison of the clinical and radiographic results of press fit condylar rotating-platform high-flexion and low contact stress mobile bearing prosthesis in total knee arthroplasty: short term results. Knee Surg Relat Res 24(1):7-13. https://doi.org/10.5792/ksrr.2012.24.1.7

21. Seon JK, Song EK, Lee JY (2005) Comparison of range of motion of high-flexion prosthesis and mobile-bearing prosthesis in total knee arthroplasty. Orthopedics 28(10 Suppl):s1247-1250

22. Zhang Z, Zhu W, Zhang W (2015) High-flexion posterior-substituting versus cruciate-retaining prosthesis in total knee arthroplasty: functional outcome, range of motion and complication comparison. Arch Orthop Trauma Surg 135(1):119-124. https://doi.org/10.1007/s00402-014-2107-4

23. Ghomrawi HMK, Lee LY, Nwachukwu BU, Jain D, Wright T, Padgett $D_{\text {, }}$ Bozic KJ, Lyman S (2020) Preoperative expectations associated with postoperative dissatisfaction after total knee arthroplasty: a cohort study. J Am Acad Orthop Surg 28(4):e145-e150. https://doi.org/10.5435/ jaaos-d-18-00785

24. Bourne RB, Chesworth BM, Davis AM, Mahomed NN, Charron KD (2010) Patient satisfaction after total knee arthroplasty: who is satisfied and who is not? Clin Orthop Relat Res 468(1):57-63. https://doi.org/10.1007/ s11999-009-1119-9

25. Baker PN, Rushton S, Jameson SS, Reed M, Gregg P, Deehan DJ (2013) Patient satisfaction with total knee replacement cannot be predicted from pre-operative variables alone: a cohort study from the National Joint Registry for England and Wales. Bone Joint J 95-b(10):1359-1365. https://doi.org/10.1302/0301-620x.95b10.32281

26. Dunbar MJ, Richardson G, Robertsson O (2013) I can't get no satisfaction after my total knee replacement: rhymes and reasons. Bone Joint J 95-b(11 Suppl A):148-152. https://doi.org/10.1302/0301-620x.95b11. 32767

27. Blackburn J, Wylde V, Greenwood R, Blom AW, Levy A (2017) The effect of numbness on outcome from total knee replacement. Ann R Coll Surg Engl 99(5):385-389. https://doi.org/10.1308/rcsann.2017.0026
28. Sharkey PF, Miller AJ (2011) Noise, numbness, and kneeling difficulties after total knee arthroplasty: is the outcome affected? J Arthroplasty 26(8):1427-1431. https://doi.org/10.1016/j.arth.2010.10.009

29. Lenguerrand E, Wylde V, Gooberman-Hill R, Sayers A, Brunton L, Beswick AD, Dieppe P, Blom AW (2016) Trajectories of pain and function after primary hip and knee arthroplasty: the ADAPT Cohort Study. PLoS ONE 11(2):e0149306. https://doi.org/10.1371/journal.pone.0149306

30. Halket A, Stratford PW, Kennedy DM, Woodhouse LJ (2010) Using hierarchical linear modeling to explore predictors of pain after total hip and knee arthroplasty as a consequence of osteoarthritis. J Arthroplasty 25(2):254-262. https://doi.org/10.1016/j.arth.2009.01.007

31. Wood TJ, Petruccelli DT, Tushinski DM, Winemaker MJ, de Beer J (2020) Nuisance symptoms in total joint arthroplasty: prevalence and impact on patient satisfaction. J Arthroplasty 35(3):661-670. https://doi.org/10. 1016/j.arth.2019.10.034

32. Rodriguez-Merchan EC (2011) Instability following total knee arthroplasty. HSS J 7(3):273-278. https://doi.org/10.1007/s11420-011-9217-0

33. King J, Stamper DL, Schaad DC, Leopold SS (2007) Minimally invasive total knee arthroplasty compared with traditional total knee arthroplasty. Assessment of the learning curve and the postoperative recuperative period. J Bone Joint Surg Am 89(7):1497-1503. https://doi.org/10.2106/ jbjs.f.00867

34. Dalury DF, Dennis DA (2005) Mini-incision total knee arthroplasty can increase risk of component malalignment. Clin Orthop Relat Res 440:77-81. https://doi.org/10.1097/01.blo.0000185757.17401.7b

35. Kolisek FR, Bonutti PM, Hozack WJ, Purtill J, Sharkey PF, Zelicof SB, Ragland PS, Kester M, Mont MA, Rothman RH (2007) Clinical experience using a minimally invasive surgical approach for total knee arthroplasty: early results of a prospective randomized study compared to a standard approach. J Arthroplasty 22(1):8-13. https://doi.org/10.1016/j.arth.2006. 06.004

36. Ackmann T, Von During M, Teske W, Ackermann O, Muller P, Von Schulze PC (2014) Anatomy of the infrapatellar branch in relation to skin incisions and as the basis to treat neuropathic pain by cryodenervation. Pain Physician 17(3):E339-348

37. Hassaballa M, Artz N, Weale A, Porteous A (2012) Alteration in skin sensation following knee arthroplasty and its impact on kneeling ability: a comparison of three common surgical incisions. Knee Surg Sports Traumatol Arthrosc 20(10):1983-1987. https://doi.org/10.1007/ s00167-011-1727-2

38. Jain S, Pathak AC, Kanniyan K, Kulkarni S, Tawar S, Mane P (2013) Highflexion posterior-stabilized total knee prosthesis: is it worth the hype? Knee Surg Relat Res 25(3):100-105. https://doi.org/10.5792/ksrr.2013.25.3. 100

39. Pilling RW, Moulder E, Allgar V, Messner J, Sun Z, Mohsen A (2012) Patellar resurfacing in primary total knee replacement: a meta-analysis. J Bone Joint Surg Am 94(24):2270-2278. https://doi.org/10.2106/jbjs.k.01257

40. Wallace SJ, Berger RA (2019) Most patients can kneel after total knee arthroplasty. J Arthroplasty 34(5):898-900. https://doi.org/10.1016/j.arth. 2019.01.047

41. Palmer SH, Servant CT, Maguire J, Parish EN, Cross MJ (2002) Ability to kneel after total knee replacement. J Bone Joint Surg Br 84(2):220-222. https://doi.org/10.1302/0301-620x.84b2.12568

\section{Publisher's Note}

Springer Nature remains neutral with regard to jurisdictional claims in published maps and institutional affiliations. 